One great point of interest lay in the extreme difficulty in distinguishing the eruption from that of an anomalous case of smallpox, even to those who had a large experience of the disease. Taking all the points into consideration, it seems to me that it was most likely a vesicating erythema of toxic origin, a diagnosis with which I believe Dr. Colcott Fox concurred, though neither of us had ever before seen an eruption of any kind quite similar to it.

A search into the literature has not furnished me with any information as to similar cases. Many cases of so-called pyæmic dermatitis have been published, but the findings differed from those in this case, and I have already given my reasons for believing this to be due to some toxic disturbance rather than infection of the lesion. I would also draw attention to the fact that most if not all such cases terminated fatally, and the material was obtained after death. In the face of more recent knowledge on the subject of terminal or agonal infection and post-mortem changes, the results so obtained should be received with the greatest reserve.

\title{
THE SCLERODERMIC TYPE OF LUPUS ERYTHEMATOSUS.
}

BY WILFRID B. WARDE, M.D., M.R.C.P.,

Assistant Physician to the Blackfriars Hospital for Diseases of the Skin.

I HAVE been permitted to state in the pages of this Journal my reasons for believing that Lupus erythematosus is not a disease in the strict sense of the word, but merely a pathological condition that may, owing to certain estimable influences, arise in the course of many perfectly distinct diseases of the skin. It will be unnecessary here to repeat these observations, since they are stated in full in recent numbers of the Journal.

If the theory there set forth is based on truth, it should be possible to demonstrate that any disease capable of producing œdema or erythema of the skin, when conditions are favourable, may give rise to Lupus erythematosus.

I am tempted, therefore, to give in series a number of cases which, 
in my opinion, go far to support this contention. In these, a condition diagnosed by competent, not to say eminent, observers as Lupus erythematosus, is found in peculiarly intimate association with sclerodermia. I will give them in order, and reserve my remarks to the conclusion of the series.

CASE 1. (Described in Hebra's Text-book-English translation-New Sydenham Soc., vol. iii, p. 107.) -Schira Katharina, 33. Patient showed well-marked sclerodermia of hands, wrists, forearms, arms, front and back of the neck and upper chest, both legs, and a slight degree of the same on the face. The patient had previously come under care on account of Lupus erythematosus. She had " on the tip of the nose a spot the size of a threepenny piece, superficially scarred at the centre and bounded at the circumference by a somewhat elevated reddish border, looking as if it had been pricked. On the edge of the upper lip was a spot with a reddish border, scarred on the surface, and of the size of a pea. The skin of the face was dotted with brown (as in chloasma) and showed a few white spots, was but slightly firmer than natural, and tolerably freely movable."

CASE 2. Exhibitor Dr. Pringle (Brit. Journ. of Dermat., 1894, p. 339 ; 1896, p. 329).-Female, aged 25. Shown for sclerodermia of the hands, forearms, and face. Fingers hide-bound in flexion. Commencing gangrene of all the finger-tips and of the skin over the knuckles (Raynaud without hæmoglobinuria). The sclerodermic condition of the face was preceded by a bat's-uing patch diagnosed by the exhibitor as Lupus erythematosus. This was said to have rapidly subsided under treatment, leaving the skin slightly thinned with patulous sebaceous gland orifices. Ears were permanently and considerably scarred.

CASE 3. Exhibitor Dr. Pringle (Brit. Joum. of Dermat., 1895, p. 30).-Female, aged 17 . On the face an accurately symmetrical bat's-wing patch of atrophied skin with patulous sebaceous ducts. The disease began last summer. The only active patch when the case was exhibited was on the lower part of the right cheek, where there was a sharply marginated patch of erythema about half an inch in diameter. Hands cold, blue, and studded with erythematous patches. Gangrene of the tips of the little fingers, and threatened gangrene of several others. On the toes many patches of purpuric 
erythema. Patient always suffered severely from chilblains, which became permanent two years ago.

CASE 4. Own collection.-Female, aged 26. An atrophying erythema, covering nearly the whole of the nose and cheeks, and present in the conchæ. The atrophy is very extensive, large areas of the skin being ivory-white and dotted over with the hugely dilated orifices of the sebaceous ducts. Disease affects the scalp severely as a deep erythema with induration and cicatricial alopecia. She has had chilblains for years. Hands and feet always very cold. Impending gangrene of the skin covering the finger-tips. Purpuric eruption on hands and feet. Deep purple mottling of the legs. Fingers much wasted.

Case 5. Described by M. Déhu (Annal. de Derm. et de Syph., 1899, p. 568).-Male, aged 55. Over the whole surface of the body the skin is thickened and indurated-a hard odema, elastic and not pitting on pressure. Marked erythema and pigmentation of the whole skin. Hands somewhat deformed by chronic rheumatism, cold and violaceous. Fingers not thickened as in myxœdema, nor thin and pointed as in sclerodactylia. On the bridge of the nose and adjacent parts of the cheeks a decolourised plaque of infiltrated and indurated skin. On the thorax, flanks, and thighs many small white cicatrices standing out against the pigmented skin. These appeared to follow from crusted excoriations. Intellect, "minus habens." Thyroid atrophied. Patient imprọved under thyroid. Diagnosis, myxœedema or sclerodermia.

Case 6. Described by Dr. Brissaud (La Presse Médicale, 1897, p. 285 ; Brit. Journ. of Dermat., 1897, p. 361).-Female, aged 42; duration, 5 years. Disease commenced with articular rheumatism and Erythema nodosum. A large abscess formed in connection with the right knee. Two years ago shrinking of the gums away from the teeth. A diffuse sclerodermia on the face, hands, and feet. Dupuytren's contracture. Intense bronzing of skin, suggesting Addison's disease. Later almost complete immobility, albuminuria, and death. When first seen she showed an erythematous condition over the malar prominences of six months' duration, suggesting Lupus erythematosus.

CAsE 7. Described by M.M. Hallopeau and Trastour (Annal. de Derm. et de Syph., 1900, p. 634).-Title, Lupus erythematosus 
developing in the course of a sclerodermia with local asphyxia of the extremities and gangrene of the phalanges, in a tubercular subject. Female, aged 30, a seamstress. Case shown in 1894 with diagnosis of sclerodermia. Since that time a series of necroses have occurred on the fingers. Patient showed a diffuse sclerodermia of the face and hands. The fingers were flexed, and the tips conical and wasted. There had been some loss of substance, and on one finger a suppurative perionychitis. Near each elbow the skin was thickened, with an exaggeration of the natural folds and some desquamation. The surface was slightly depressed. In front of each knee the skin was hyperpigmented and transversely striated. A few hyperpigmented and atrophied patches occurred on other parts of the body. The skin of face was shining; lips thin. On the nose were decolourised and red plaques, irregularly and confusedly intermingled. One of these occupied the tip, and was surrounded by an erythematous areola that projected slightly. On the right side of the nose there was a decolourised patch surrounded by an erythematous zone, and a similar patch on the other side. These were separated from the tip by an erythematous tache, disappearing under pressure of the finger, and beginning to atrophy and turn white. On the posterior part of the right cheek was a plaque 6 by $4 \mathrm{~cm}$. This presented two colorations. In the lower and inner two-thirds, and also at the superior extremity, it was white. In the upper and outer third it was erythematous, desquamating slightly, and disappeared under pressure. The skin surrounding this plaque was hyperpigmented, and one sees on its surface some islands of pigment. There was no glandular dilatation. The surface was depressed. On the left cheek was a similar and smaller patch completely decolourised, depressed, and surrounded by a pigmented border. The patient showed in addition moist râles, with dulness at the left apex of the lung.

There is a remarkable family resemblance between these seven cases. Case 5 was of doubtful nature, and there is nothing to show that the indurated white patch on the nose and adjacent parts of the cheeks was preceded. by an erythema. The description given of the case corresponds closely with that of many recorded cases of generalised sclerodermia. Hence I have included it.

Of the remainder, four (Nos. 1, 2, 6, 7) suffered from diffuse sclerodermia of the face and hands. In Cases 1 and 7 the 
sclerodermia was present in patches on other parts of the body, and Case 6 had diffuse sclerodermia of the feet as well as of the face and hands. In 2 and 7 there was gangrene of the finger ends.

The other two cases (Nos. 3 and 4) do not actually show sclerodermia, but they suffered from a severe form of Raynaud's disease, Case 3 showing the asphyxial type with gangrene of the finger ends, Case 4 showing the atrophic type, which is in reality a sclerodactylia, with impending gangrene of the finger ends.

The chief impression one has after reading the series is the prominence of atrophic scarring in all the cases, and the completeness and rapidity with which it appeared in some.

In Case 1 there is merely a red border. In Case 2 the notes make it clear that the erythema rapidly disappeared, "leaving the skin slightly thinned with patulous sebaceous gland orifices." In Case 3 the atrophy is nearly complete in about six months, since it is noted that the appearance corresponded to that seen in the last case, the only active patch remaining being " a sharply marginated patch of erythema about half an inch in diameter." In Case 4 the atrophy was remarkable, and there was the same confused mingling of atrophic and erythematous patches so conspicuous in Case 7. In this case, as in the preceding, a purpuric erythema was noted on the hands and feet.

In Case 5 the atrophy is complete, but owing to reasons given the case cannot be considered.

Case 6 is interesting, since the erythematous condition on the malar prominences evidently gave place to sclerodermia. In Case 7 the atrophy is very conspicuous, and the picture given exactly recalls that found in Case 4. In this case, too, it is noted that the skin surrounding the patches on the cheeks is hyperpigmented. This is a very suggestive point, since in my experience disturbances of pigmentation are of very rare occurrence in other cases of Lupus ery thematosus, whereas in sclerodermia they are exceedingly common.

It is easy to establish the fact that in some cases of sclerodermia erythema is a conspicuous feature. Many cases are on record, and I will mention a few of them.

The late Dr. Cavafy (Brit. Journ. of Dermat., 1896, p. 275) showed before the Dermatological Society of London a woman, aged 50 , suffering from morphœea. He had previously shown the case in 
1895, when she was said to be suffering from a pale erythema in patches of the lower extremities. In the interval the patches had enlarged and fresh ones appeared. Six months before the second exhibition all the patches hardened; the colour faded and gave place to yellow, scar-like skin surrounded by a narrow zone of violaceous erythema. There was some ulceration in the right popliteal space.

Dr. Abraham (Brit. Journ. of Dermat., 1895, p. 53) describes a case, a female, with patches of morphoea on the left shoulder, arm, and forearm, and erythematous blotches on the cheek.

Dr. Abraham (Brit. Joum. of Dermat., 1899, p. 472) describes another case of circumscribed sclerodermia in a man of 70. I often saw this man. He had vivid red, indurated, rounded patches on the back, chest, abdomen, thighs, and legs, and an indurated erythema on one side of his face.

Dr. Graham Little (Brit. Journ. of Dermat., 1902, p. 467) showed a boy, aged 11, with a band of sclerodermia following the supra-orbital branch of the fifth nerve. This band remained red for two years before it began to change colour and assume the aspect of a scar.

In all these cases-and more could be quoted-there is really an atrophying erythema that corresponds closely with that encountered in the seventh case of this series. And the comparison is not altogether fair, since the cases last quoted are instances of circumscribed sclerodermia, whereas those in the series are of the diffuse type, in which the atrophy is more intense and more rapid.

Hence it is difficult to put forward any good reason why the cases in the series should not be regarded as really sclerodermic in nature.

There is an interesting case described by Mr. Hutchinson (Archives of Surgery, 1893, p. 365) that illustrates the difficulty of diagnosis. The case was sent to Mr. Hutchinson by Dr. Abraham. I will quote it as it is given :- "Exactly in the centre of each flush patch of the cheek there is a round shilling-sized area like ivory. The reasons for believing that these patches result from Lupus erythematosus, and not from morphoea, are the following:- Their margins are distinctly erythematous and slightly swollen, and there are some little red discs close to them (satellites), which she says well represent the early stage of the patches on her cheeks. There is also some roughness over the whole of the bridge of the nose, 
and the patient states that she had formerly patches in that position. . . . The patient suffers very much from chilblains. Her fingers are covered with erythematous papules, some of which present depressions in the middle."

This case was, I believe, sent to Mr. Hutchinson as an example of morphœa. He held it to be Lupus erythematosus. According to my view it could be both. For I have contended that any erythema or erythematous eruption can, if the circumstances be favourable, undergo atrophy, and this atrophy represents the best mode of healing that the part is capable of at the moment. Usually the healing is greatly prolonged, owing to the fact that the vessels of the part are merely damaged but not destroyed, and also to the important fact that the exciting causes, e.g. cold, exposure to sun, etc., are still operating. Then the diagnosis of Lupus erythematosus is unquestioned. But in other cases the passage into atrophy may be so rapid and complete that the case is labelled sclerodermia or idiopathic atrophy of the skin from the beginning.

In the cases of the series the circumstances are distinctly unfavourable to the complete restitutio ad integrum of any skin lesion,- that is to say, decidedly favourable to atrophy or dry necrosis. And that is what usually occurs. The chilblains, from which they suffer so much, persist, and frequently undergo central necrosis. The follicular lesions of the legs and arms, so common in all subjects, also necrose in the centre, owing to their inability to heal or to undergo frank suppuration. In this condition they are often classed as toxi-tuberculides, on what appears to me to be as insufficient evidence as that on the strength of which Lupus erythematosus is placed in the same group. Such patients are obviously prone to tubercular affections, as also to simple catarrhs of every description. Owing to their circulatory defects they are all "bad lives" from an insurance point of view. But it does not in the least follow, nor is it probable, that these necrosing skin lesions are in any way tuberculous in nature.

A very interesting case is recorded by Sir Stephen Mackenzie (Brit. Journ. of Dermat., 1898, p. 51). A female aged 26. Patient came under the exhibitor's charge in 1886 for patches of. morphœa on each side of the trunk, which shortly underwent involution, leaving pigmented patches, which are still present. At the second 
time of exhibition the helix and lobule of both ears were withered and contracted, and on the lobules were small patches of depressed (cicatrised) skin with dry crusts. On the face in front of the right ear were two pea-sized areas having a punched-out appearance, the base being red and smooth. On the scalp were curious irregular depressed areas $(1 \mathrm{~mm} . \times 0.5 \mathrm{~mm}$.). They have abrupt edges, a dry and scar-like base. On the left side of the face was an irregular erythematous patch $4 \mathrm{~mm}$. long. The lesions on the ears started as small hard lumps, which enlarged, became red, and discharged blood and matter. For two years they alternately healed and discharged, leading to gradual destruction. All the members of the Dermatological Society present agreed that the lesions were of the nature of Lupus erythematosus.

I have excluded this case from my series, but with the feeling that it is closely allied, and that it should be considered together with them. The withering of the ears that occurs in so many cases of Lupus erythematosus is singularly like that encountered in the diffuse type of sclerodermia.

The main difference between the two diseases is that Lupus erythematosus attacks the superficial parts of the skin, whereas in the majority of cases sclerodermia attacks the deeper layers, and especially the subcutaneous tissues in which the larger vascular trunks lie.

But it is interesting to note that the more superficial the sclerodermia the more is it apt to resemble Lupus erythematosus.

Another interesting and suggestive point is that there are certain histological resemblances between the three diseases, Lupus erythematosus, Lichen planus, and the superficial type of Sclerodermia called by Unna " card-like." In Lichen planus atrophicus the two last named come so close together as to be almost identical.

The general picture of the three diseases is by no means the same, but the details bear a close resemblance. There is the same marked disturbance of the basal layer of the epidermis in all, the same infiltration of small cells of a similar type lying immediately beneath the epidermis, and surrounding the ducts, follicles, and blood-vessels. These cells are poor in protoplasm, and appear to have few processes. In sclerodermia they may disappear rapidly before the advancing sclerosis; but where present they closely 
resemble those met with in the other two, both as to type and arrangement. The main difference lies in the behaviour of the vessels. In Lichen planus the vessels are relatively little damaged, and are able to return to their normal condition as soon as the cell collection has disappeared. In Lupus erythematosus the vessels are dilated in an extreme degree, and usually the only possible termination is a gradual obliteration, leading to scar-formation. This naturally may take many years to happen.

In sclerodermia the vessels are narrowed or obliterated from an early stage. As a consequence the cell collection is slight, or may be absent, and the passage into scar tissue is extremely rapid. It is well to note how much an odema of the tissues favours cell multiplication and hinders their disappearance. So long as the cells persist, a perfect scar cannot result, since such a scar is practically acellular.

Histologically, therefore, there is a close connection between Lupus erythematosus and the superficial types of sclerodermia. So close is it, in fact, that it is possible to conceive of them as being the same malady influenced merely by the power of resistance of the vessels. In the latter the vessels give way at once and become entirely obliterated. Hence the rapid scar-formation and the great tendency to necrosing lesions. In the type of Lupus erythematosus now under consideration in this paper the obliteration of vessels is apparently very rapid, as evidenced by the passage of the erythema into atrophied and sclerosed patches.

In this connection a case of Lupus erythematosus disseminatus described by the late Dr. Cavafy (Brit. Journ. of Dermat., 1897, p. 328) is singularly interesting.

A female, aged 22. Disease commenced on the hands seven years before, and slowly increased till the time of exhibition. The dorsum of the fingers and ulnar border of the hands were covered with vivid red, slightly scaly patches, in many cases become confluent to form large patches. The patches have irregular outlines, are bounded by sharp borders, and are slightly depressed. The tips of both little fingers atrophied. A few scaly patches were present on the palmar aspect of the fingers, and on the thenar and hypothenar eminences. In cold weather fingers became dead, but there were no chilblains. Four years ago patient suffered from severe inflammation of face, ears, and back, with some 
fever. It was first called erysipelas and then eczema. The inflammation subsided, leaving the ears and back scarred, and some patches on the face which have spread since. Condition when exhibited:Ears stiff, red, scaly, superficially scarred. Pale red scaly patches on the right cheek, tip of the nose, and on the chin. These appear to be involuting. Some show slight pigmentation. The upper lip swollen, sore, red, scaly, the swelling extending to the inner mucous surface. Scalp free. On the outer aspect of the right arm, over the deltoid insertion, an oval, dull red, sealy patch. The back, from the upper interscapular region to the lower dorsal region, occupied by a large grey superficial scar.

It is fair to use the word "sclerodermic" to describe a case like this, without necessarily implying that the two processes are allied or identical. My own personal belief is that sclerodermia, like Lupus erythematosus, is not a distinct disease, but merely a pathological state occurring in the course of other diseases, of which the chief are rheumatism and urticaria. I believe further that sclerodermia forms the end of a pathological chain of which Lupus erythematosus is the middle, and that the cases under consideration are on the boundary line between the two. However, personal beliefs are of little value, and I hope to be able to take up the subject again on some future occasion.

Conclusion.-There occurs in patients who suffer from diffuse sclerodermia of the face and hands, or from Raynaud's disease, a form of atrophying erythema, marked by the preponderance of the atrophy over the erythema and by the rapidity with which the atrophy often ensues. These patients show a marked tendency to gangrene of the finger ends, and to the appearance on the hands, and often on the feet, of erythematous lesions, sometimes purpuric in character. 'Till more accurate information is forthcoming as to the relationship of Lupus erythematosus and sclerodermia, these cases can very well be provisionally known as the sclerodermic type of Lupus erythematosus. 